Having thus very briefly considered the baths we now come to what may be looked upon as the most important part of the treatment-viz., the resisted exercises. The great principle underlying the treatment is to diminish the peripheral resistance to the onward flow of blood and so to make it easier for the heart to perform its work. There are three ways in which this can be done by exercises: (1) by acting on the muscular system ; (2) by acting on the respiratory system; (3) by acting on the digestive system.

1. Let us consider what takes place when a muscle is at work. It alternately contracts and relaxes. When a muscle contracts it hardens; the intra-muscular and intrafascicular blood-and lymph-vessels become squeezed, the fluid is driven out, and owing to the valves which are placed in the veins and lymphatios the flujd is driven towards the heart. This causes a relative fluid-emptiness in the muscle, so that when it relaxes a suction is created drawing. the blood towards and into the muscle and away from the heart Each muscle may, indeed, be looked upon as an additional heart. As the heart itself is the great central pump in the body, so is each individual skeletal muscle a peripheral pump which by alternately contracting and dilating pumps the blood onwards. If a single muscle were to be thus acted upon the result might be infinitesimal, but when groups of muscles, say of a limb, are made alternately to contract and relax, the influence becomes important. The fact that muscular contractions really do have a marked effect can be demonstrated by examining the pulse; for whereas the pulse before the exercises may be irregular and quick the almost invariable condition found after exercising is a slower and more regular pulse-rate. I have seen instances where there has been a difference of 20 beats a minute before and after exercising. Besides thus mechanicaly helping on the blood-stream, a more remote result is that waste products and exudations with which the muscle probably are infiltrated are cleared away and that the metabolism becomes more active. It is easy, then, to understand why resisted exercises should be helpful in heart disease. An over-full and dilated heart struggling to contract and to drive the blood onward against great peripheral resistance finds its work eased and feels itself able to perform its function with less output of energy, the result of which is that its action becomes slower and more regular This result may not last long to begin with-perhaps a couple of hours-but by persevering with the treatment day by day for some time it cannot but permanently improve and strengthen the diseased organ. The physiological effect of resisted muscular exercises on an over-full and dilated heart is very much the same as the effect of emptying an overdistended bladder. The analogy is complete, for are they not both hollow muscular organs?

2. By acting on the respiratory system. It is well known that during an inspiration the large veins in the chest dilate, as do also the cardiac auricles. A suction action is thus established the effect of which is to draw the blood away from the periphery towards the heart. But besides this, by alternately filling and emptying the lungs of air by deep inspirations and expirations the circulation through the pulmonary capillaries and vessels is very much facilitated, for when an air-vesicle dilates during inspiration and resiles during expiration the capillaries in the vesicular walls are alternately put on the stretich and contracted, and this tends strongly to relieve any congestion which may be, and often is, present in the lungs in chronic heart disease. There is yet another way in which respiratory exercises are beneficial-viz, by ensuring a more thorough aeration and oxygenation of the blood, for thus more blood is made to course through the pulmonary circulatory system in any given time.

3. By acting on the digestive system. A common symptom in patients suffering from chronic cardiac disease is irregularities in the performance of the abdominal organs, not-at least in the earlier stages-owing to any actual local lesion, but as the result of the sluggish manner in which the circulation is carried on. Thus we get a congestion of all the abdominal viscera, which shows itself in a deficient secretion of the liver, the stomach, the pancreas, and the bowels, and in the presence of albumin in the urine. The raison d'ettre of the treatment is forcibly shown here. The passive conges. tion just mentioned offers a considerable resistance to the flow of blood towards the heart, thus rendering the backward pressure extremely felt by an enfeebled organ. An improvement is brought about indirectly by acting on the muscular and respiratory systems, as I have already endeavoured to show, and directly by stimulating and kneading the abdominal viscera through the abdominal walls. Ubi stimulus ibi affuxus, or wherever there is a demand for energy thither does the blood flow. The circulation in the abdominal viscera becomes roused, there is a demand for fresh blood, the used-up blood is moved on, greater activity takes place in the various abdominal organs, and the bowels, the liver, the stomach, and the kidneys take on a healthier physiological action.

When writing a movement prescription, then, attention should be directed towards these three systems and a typical prescription would be very much as follows: (1) Arm exercises, (2) respiratory exercise, (3) leg exercises, (4) respiratory exercise, (5) trunk exercises, (6) kneading of the abodominal viscera, (7) respiratory exercise. During the performance of the exercises-which should be given slowly - the pulse should be carefully watched, as should also the patient's respirations, for the slightest evidence of distress, either cardiac or respiratory, must be taken as an indication that a certain exercise may be too strong or unsuitable. It is well that the patient should rest in the most comfortable position for an hour after each treatment, which should occupy about half an hour each time.

Let me, in conclusion, urge members of the medical profession to take up this treatment personally, instead of leaving it in the hands of nurses and assistants. It is becoming more and more recognised what a powerful therapeutic agent for good or evil this treatment is, not only in heart disease, but in many chronic complaints, and it is but right that it should be in the hands of the profession. Then, and then only, will it take its due place in the long list of the various methods of treatment. - I am, Sirs, yours faithfully,

Oтто HoLsT, M. R.C.S. Eng., L.R.C.P. Lond. Eastbourne, April 28th, 1902

\section{OPERATION FOR SUSPECTED STONE IN THE KIDNEY.}

To the Editors of THE LANCET.

SIRs, - In reading the interesting series of cases of Operation for Suspected Stone in the Kidney and the clinical remarks on them published by Mr. Edmund Owen in THE LANCET of April 19th, p. 1105, I am reminded of a case that was under my care in the York County Hospital in 1900 .

The patient was a man, about 30 years of age, who for some time before I saw him had been suffering from pain over the right kidney with frequent attacks of hæmaturia and had also passed several small pieces of uric acid calculi. As the pain increased in severity and frequency I cut down upon the right kidney, turned it out, and punctured it in five or six places, but I failed to detect any stone. The kidney was replaced; the wound healed up and since then the patient has been entirely free from pain and hæmaturia. $\mathrm{He}$ is now in the South of England and I heard of him a few weeks ago, the report being to the effect that he had been entirely free from all his old symptoms since the operation, that he had put on flesh, and that he felt better than he had done for years. Is it possible that the various punctures may have relieved tension and so produced amelioration of his symptoms?

I am, Sirs, yours faithfully,

York, April 22nd, 1902

$$
\text { WIILIAM H. JALLAND, F.R.C.S. Eng. }
$$

To the Editors of THE LANCET.

SiRs,-Few surgeons will, I think, dissent from the views so ably expressed by Mr. E. Owen in your issue of April 19th, p. 1105. It seems, however, unnecessary to refuse assistance from the $x$ rays through fear of one's judgment being unduly influenced. In a woman on whom I operated a fortnight ago the only indications of calculus were persistent pain in the left loin, from which she had suffered daily for four years, and the occasional presence of a trace of albumin in the urine. A series of excellent radiographs taken by Mr. W. J. D. Bromley, the senior house surgeon at the Lancaster Royal Infirmary, utterly failed to indicate the presence of a stone; yet from the pelvis of this kidney I removed an oxalate calculus weighing 48 grains.

The two cases first mentioned by Mr. Owen seem to present little difficulty in diagnosis. Both the subjects were young men who suffered from typical attacks of renal colic accompanied by albuminuria. The only reasonable ground of doubt appears to have been the absence of hæmaturia. 
Blood is often absent from the urine in these cases and, moreover, is often overlooked when present. One of my former teachers used to advise his patients to patronise a certain line of omnibuses which were famed for their rigid springs and also for the rugged roads that they traversed. After this he had the urine which was passed during the following 24 hours collected in a conical vessel. An examination of the deposit very rarely failed to detect bloodcells. I believe that attacks of "colic" are only present in a minority of cases of stone in the kidney. In many the pain is constant and although subject to exacerbationswhich, however, are not paroxysmal in nature-is unaccompanied by sickness or hæmaturia. Increased frequency of micturition is common, but as it also occurs in many other conditions is not of great value as a. diagnostic sign. Any reaction to Mr. Jordan Lloyd's test is in my experience exceptional.

And now as regards two points in the technique of the operation. We are frequently told that it is advisable to plug the wound in the kidney. I fancy that most surgeons have now discarded this practice. The kidney substance is best brought together by mattress sutures. No urine exudes and no drainage either of the kidney or the outer wound is required. In reference to the site of the incision into the kidney the experience of those who have used that advocated by Brödel would be of great value. I used it in a recent case but cannot say that $I$ noticed any marked diminution in the amount of bleeding.

I am, Sirs, yours faithfully,

Lancaster, April 21st, $1902 . \quad$ A. STANLEY BARLING.

\section{THE ROYAL NAVY MEDICAL SERVICE.}

To the Editors of THE LANCET.

SIRS, - In the regulations in connexion with the above recently issued by the Admiralty it is stated that early promotion to the rank of staff-surgeon may be granted to those surgeons who before entry held the post of house surgeon to a civil hospital. Would it not be better that a naval surgeon should be allowed to hold a house surgeoncy for six months at his hospital at any time within 12 months of his entering: the service, provided he could obtain nomination for such a post, his time and pay counting during such house surgeoncy? At present candidates are deterred from seeking the post of house surgeon before entering the service on account of the loss of time and seniority it would entail. If they were to be permitted to hold such a post after entering it would be for the benefit of the service and would induce the best class of men to join. The candidate who takes his house surgeoncy before entry will always run the risk of finding himself junior in the service to his junior in experience.

There is a further rule requiring naval surgeons to undergo a post-graduate course of three months' duration at a metropolitan hospital once in every eight years, receiving full pay, lodging, and provision allowance, \&c., but being required to pay himself the necessary fees for such a course. The rule concludes by stating that the officer will be required to produce separate certificates of efficient attendance in the following: (1) medical and surgical practice of a hospital, (2) a course of operative surgery on the dead body, (3) a course of bacteriology, (4) a course of ophthalmic surgery, and (5) a practical course of skiagraphy. The fee for this course, 33 guineas, is a severe tax.

Ought it not rather to be required that the naval surgeon should put in a three or six months' course quite free of all expense at least once in every six years, or preferably once in every three years-i.e., at the end of each commission? Should he not also be encouraged to take higher qualifications? A course of six months' study of State medicine would be of the greatest value in the service, and a surgeon who was willing to qualify and take the diploma in Public Health should, I think, be considered eligible for special promotion quite as much as a surgeon who has been fortunate enough to hold the post of house surgeon. As matters stand at present as warden of a meaical college $I$ am obliged to advise candidates for the Naval Medical Service to enter the service as early as possible and without seeking to hold house appointments, but if the suggestions I have made were adopted the candidates could enter just as early and prove far more valuable men in the end.

$$
\text { I am, Sirs, yours faithfully, }
$$

$$
\text { MUNRo SCOTT, }
$$

April 30th, 1902. :Warden of the London Hospital Medical College.

\section{SMALL-POX ON THE RIVIERA.}

\author{
(From OUR SPECIAL SANITARY ComMissmoner.)
}

\section{A Bad Season.-The Effioacy of Revacoination at Nice.- Small-pox and the British and American Colony.}

THE Riviera winter season which has just concluded has proved disastrous in some places and nowhere is it qualified as a good season, aithough, as usual, the Principality of Monaco is the last to be affected by any evil circumstances that may arise. Indeed, the hotels, in spite of their numbers, have been well filled; and early in March, when I arrived at Monaco, it was with some difficulty that I coula secure a suitable room. Now, of course, the great bulk of visitors have left and this is the moment when all concerned have time to pause and to consider the situation.

There are two principal causes that have produced the unfarourable result-namely, small-pox and the war. No explanation is necessary to show that the war has compelled many British families and tourists to postpone the pleasure and the expense of wintering in the south. This is an unhappy circumstance over which local enterprise and the municipalities of the Riviera resorts had no control. The same cannot be said with regard to the prevalence of smallpox. Ever since British visitors have frequented the Riviera and English papers have published descriptions of the various attractions of this favoured coast, protests have been uttered against the want of proper sanitation and efficient drainage. As a consequence there have been various improvements effected; but more remains to be done than has actually been achieved. In one respect especially there has been the most reprehensible neglect and that is in regard to the provision of isolation hospitals for infectious cases. This great grievance was rendered distressingly obvious during this winter's season by the prevalence of small-pox. Nothing can be more alarming and painful than the position of a person away from home and country and stricken down by small-pox while staying in an hotel. In England a stranger would be removed in a proper ambulance by welltrained attendants to the fever or small-pox hospital where he would find the best sanitary conditions, medical attendance, and highly trained nurses. The room in his hotel would be thoroughly disinfected and the risk incurred by the other inhabitants of the hotel would be reduced to a minimum. If, on the Riviera, the authorities insist on removing the patient they can only take him to the general hospital where he will be nursed by untrained sisters who know more about proselytising than about nursing and he will be a source of danger to the other patients. If he is allowed to remain in the hotel he endangers his fellow residents and is not in suitable surroundings for efficient treatment.

In such circumstances it is not surprising that the fear of small-pox has kept many intending visitors away from the Riviera. That it should have this effect is so obvious that the authorities concerned have done their best to conceal the fact that small-pox cases have occurred in several of the winter resorts. But the policy of concealment always defeats its own ends. Absolute concealment is impossible and the absence of official information naturally gives rise to exag. gerated rumours. Thus, we find in the New Free Press of Vienna a statement that there were during the season from 400 to 500 deaths from small-pox at Nice. This is undoubtedly an exaggeration. A few cases of small-pox occurred at Nice during the month of November, but it was not till Dec. 14th that several cases were notified on one and the same day, and the disease may then be said to have assumed an epidemic aspect. The disease was exceptionally virulent : the proportion of mortality was equal to about 32 per cent. of the cases. But this outbreak has in any case served one good purpose, for it has once more demonstrated the efficacy of vaccination. It may also be claimed that it has not been unconnected with economic and insanitary conditions. Dr. Balestre, director of the Bureau d'Hygiène of Nice, informs me that the inhabitants of the old town suffered most. He visited the two worst streets and the poverty, overcrowding, and filth prevailing there were beyond all description. The tall houses in these narrow, winding, steep, and picturesque streets have simply no sanitary accommodation at all. In the streets there are some gratuitous latrines but there are no closets in the houses. The inhabitants, for the most part very poor Italian labourers, 